\title{
MOTIF SAKURA WARNA ALAM PADA KAIN PANJANG
}

\author{
Nuri Ningsih Hidayati
}

\begin{abstract}
ABSTRACK
In this world, many countries have a beautiful flower that became icons as well as Dutch Tulip flowers but the author is more interested in Sakura flowers that are part of Japan. In addition to its beautiful Sakura has turned out to be an important symbol, which is often associated denganperempuan, life, death, and also a symbol to express the bond between human beings, courage, sadness, and joy. No wonder if Sakura much admired for its beauty. Sakura has become a part that can not be separated in Japanese culture one of which can be seen when the cherry flowers bloom in spring. With an overview of all events of the flowering cherry created new innovations in work such as engineering, color, and a unique motif.
\end{abstract}

Keywords : motif, sakura, natural color, long cloth

\section{ABSTRAK}

Di dunia ini banyak negara yang mempunyai bunga indah yang menjadi icon seperti halnya Belanda dengan bunga Tulip akan tetapi penulis lebih tertarik pada bunga Sakura yang merupakan bagian dari Jepang. Selain bentuknya yang indah ternyata Sakura mempunyai simbol penting, yang kerap kali dikaitkan denganperempuan, kehidupan, kematian, serta juga merupakan simbol untuk mengekspresikan ikatan antar manusia, keberanian, kesedihan, dan kegembiraan. Tidak heran jika Sakura banyak dikagumi karena keindahannya. Sakura sudah menjadi bagian yang tidak bisa dipisahkan dalam kebudayaan Jepang salah satunya bisa dilihat ketika bunga Sakura mekar di musim semi. Dengan gambaran semua peristiwa mekarnya sakura tercipta inovasi baru dalam berkarya berupa teknik, warna, dan motif yang unik.

Kata kunci: motif, sakura, warna alam, kain panjang

PENDAHULUAN

\section{Pendahuluan}

Penciptaan karya seni tidak lepas dari pengaruh alam misalnya kekaguman akan keindahan, keindahan suatu anganangan, maupun kejadian yang terjadi pada alam. Alam semesta dan dinamika kehidupan makhluk hidup di dalamnya menyimpan hal yang menarik untuk diamati dan direnungkan. Ketertarikan itu menimbulkan gagasan seorang seniman dalam menciptakan suatu karya seni yang ditentukan oleh berbagai faktor di dalam lingkungan maupun pengalaman pribadinya, termasuk kebutuhan manusia yang membutuhkan keindahan, ketenangan, dan kedamaian. Menciptakan karya yang inovatif membutuhkan daya kreativitas tinggi. Proses kreativitas yang tampak indah hakikat citra keindahan

* Nuri Ningsih Hidayati, Mahasiswa S-1 Jurusan Kriya, Fakultas Seni Rupa, Institut Seni Indonesia Yogyakarta. 
Tuhan dan ketulusan dalam berkarya, sehingga membutuhkan waktu yang lama dalam perwujudannya. Perpaduan bahan dan teknik yang dipakai harus melalui percobaan dan penelitian terdahulu untuk mencipta karya yang berwarna natural dan berciri khas.

Keindahan alam bagi penulis diekspresikan dalam keindahan bunga, semua orang mengetahui betapa indahnya bunga selain karena memiliki warna dan semerbak wangi yang mempesona, ternyata bunga juga mempunyai makna yang berarti. Dunia ini banyak negara yang mempunyai bunga indah yang menjadi icon seperti halnya Belanda dengan bunga Tulip akan tetapi penulis lebih tertarik pada bunga Sakura yang merupakan bagian dari Jepang.

Warna bunga tergantung pada spesiesnya, ada yang berwarna putih dengan sedikit warna merah jambu, merah keungu-unguan, kuning muda, hijau muda atau merah menyala. Bentuk dan warna bunga-bunga ini telah lama dikaitkan dengan lambang kemurnian dan kesederhanaan. Selain bentuknya yang indah ternyata Sakura mempunyai simbol penting, yang kerap kali dikaitkan denganperempuan, kehidupan, kematian, serta juga merupakan simbol untuk mengekspresikan ikatan antar manusia, keberanian, kesedihan, dan kegembiraan. Tidak heran jika Sakura banyak dikagumi karena keindahannya. Sakura sudah menjadi bagian yang tidak bisa dipisahkan dalam kebudayaan Jepang salah satunya bisa dilihat ketika bunga Sakura mekar di musim semi.

Berdasarkan data dari majalah dikatakan bahwa kejadian-kejadian saat istimewa merupakan suatu moment. Moment tercantik Sakura saat bersemi adalah saat sakura bermekaran seperti Badai Sakura, Terowongan Sakura, Sakura gugur dan menonton Sakura dengan cara piknik di bawah pohon Sakura. Namun keindahan sakura hanya bisa terjadi setahun sekali mulai di akhir musim dingin dan bunganya mekar setahun sekali tepat di akhir bulan Maret sampai awal bulan April dan waktu mekarnya tidak lama.( Majalah Sedarlah Japan, 2000)

Banyak cara untuk menikmati keindahan sakura, sebagai seorang yang berada dalam dunia seni salah satu cara yang dilakukan dengan pembuatan karya seni dengan sumber ide Sakura dengan menggambarkan keindahan dan kejadian yang timbul ketika Sakura mekar. Berdasarkan hasil paparan Fukumoto bahwa penempatan Sakura seringkali diterapkan pada kipas, guci serta pakaian khas di Jepang. Penerapan pada kain panjang dengan gambaran semua peristiwa mekarnya sakura diharapkan tercipta inovasi baru dalam berkarya berupa teknik, warna, serta motif yang berbeda.

Melalui sebuah pemikiran dan pengamatan serta ketertarikan akan keindahan alam, Sakura menarik dan pantas untuk diekspresikan menjadi sebuah karya seni batik. Penulis membuat karya kain panjang dengan Sakura sebagai ide penciptaan yang digubah sedemikian rupa sesuai dengan kemampuan dan selera penulis. Ekspresi dalam sebuahkarya fungsional berupa kain panjang dengan menggunakan teknik batik. Penulis bisa mengekspresikan keindahan Sakura dengan menvisualisasikan dalam karya dan juga 
diaplikasi sentuhan zat pewarna alam dengan teknik colet maupun celup tutup.

\section{Hasil Pembahasan}

Proses penciptaan ini menghasilkan delapan karya seni. Berdasarkan fungsinya kain panjang selain digunakan untuk jarit, sarong digunkan juga untuk kain lilitan sesuai responsif pemakaianya hinga tercipta bentuk- bentuk yang indah seperti halnya gaun, dress dan lain lain.

Gambar-gambar dibawah ini merupakan karya yang telah diciptakan.

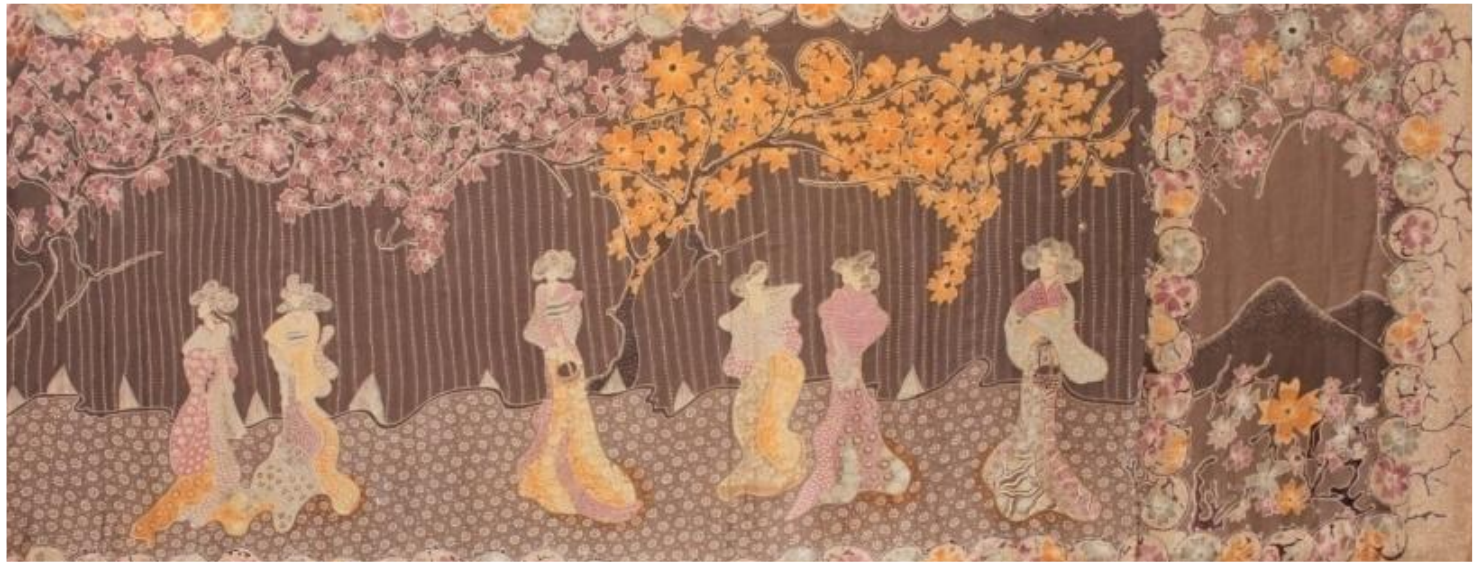

Judul : Sakura Semi

Media : Kain Sutera

Ukuran : $115 \times 260 \mathrm{~cm}$

Tahun : 2013

Warna : Biza, Tingi, Secang, Indigo, Soga, Tegeran, jolawe

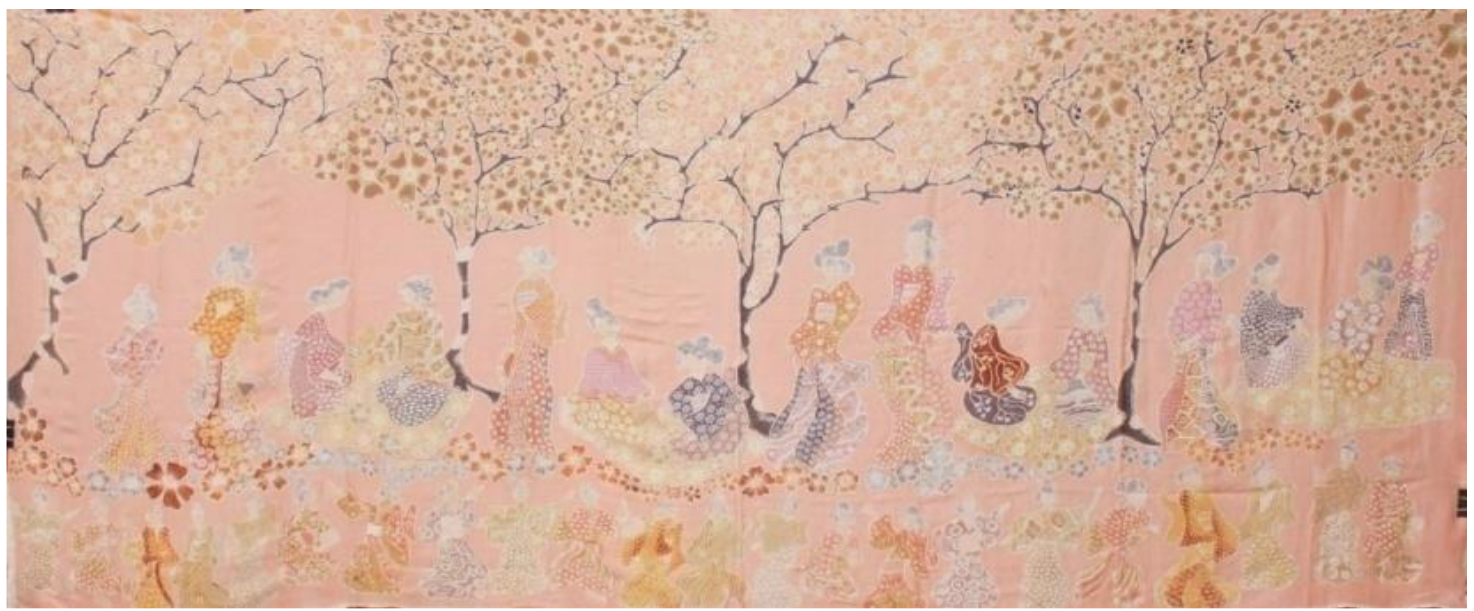

Judul : Menonton sakura

Media : Kain Sutera

Ukuran : $115 \times 260 \mathrm{~cm}$

Tahun : 2013

Warna : Kulit Manggis, Marenggo, Daun Mangga, Jolawe, Indigo, Tingi, Tegeran, Soga, Daun Jati, Bugenfil, Akar 


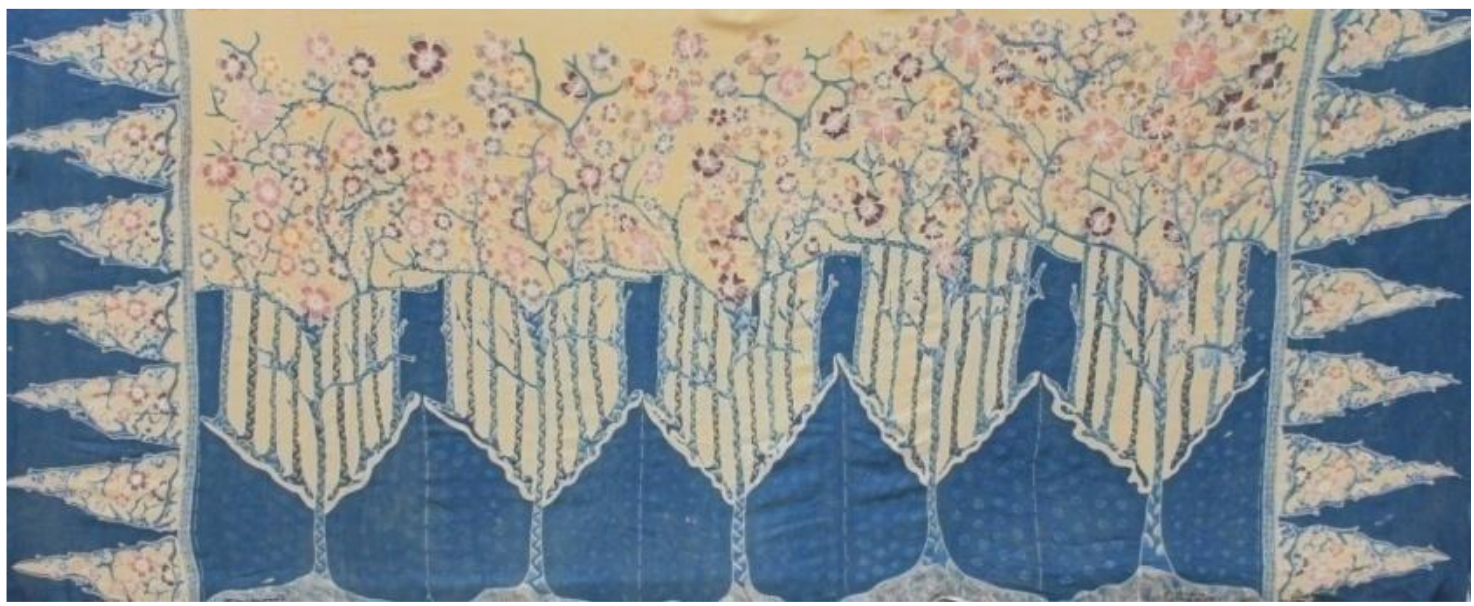

Judul : Terowongan Sakura

Media : Kain Sutera, Ukuran : 115×260cm, Tahun : 2013

Warna : Kesumba, Daun Jati, Secang, Tingi, D.Marenggo,

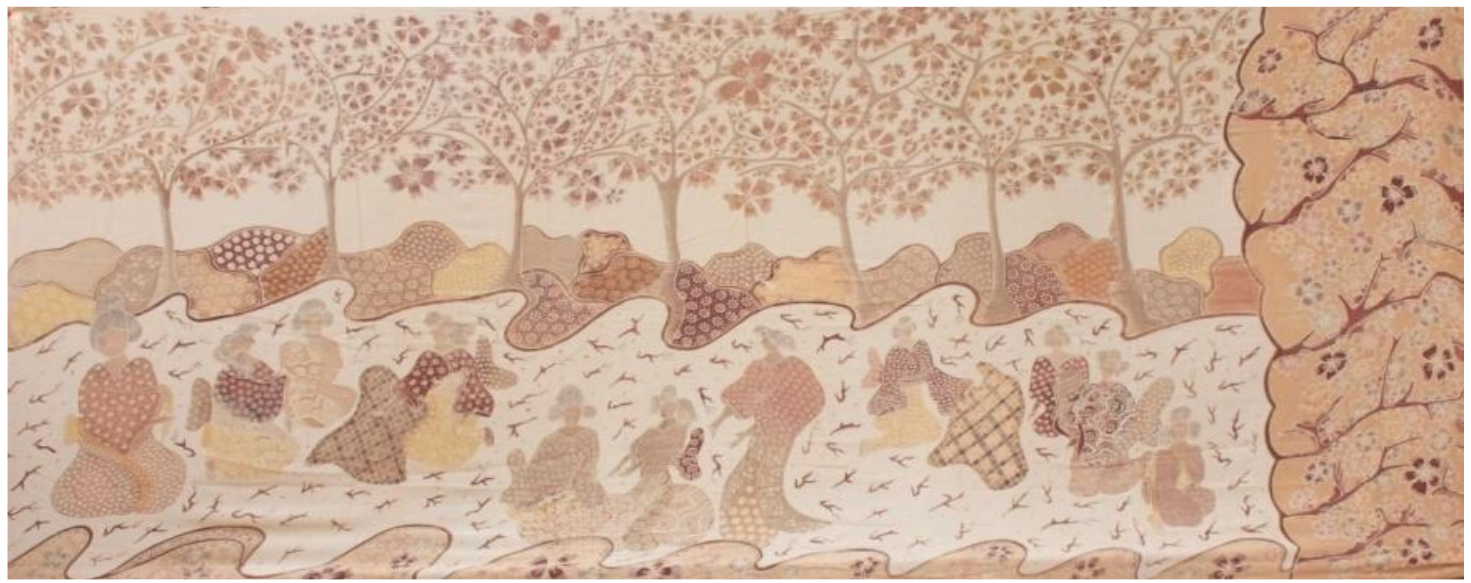

Judul : Gugur Sakura

Media : Kain Sutera, Ukuran : 115x260cm , Tahun : 2013

Warna. : Biji Pepaya, D.Jambu, Benguk, Secang, D.Jati, Akar pace, Kulit Manggis, Celung, Indoigo, Kesumba, Tegeran, Teh, Marenggo, Tingi , Jambal

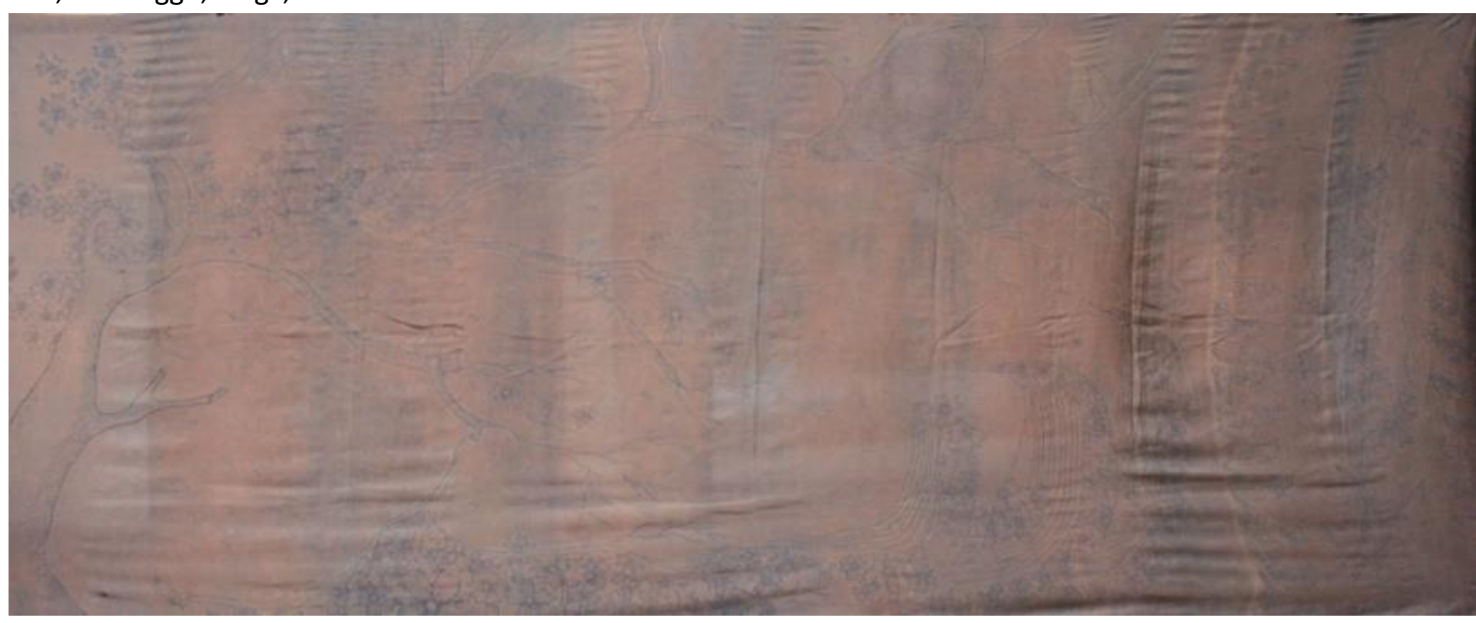

Judul : Badai Sakura

Media : Kain Sutera, Ukuran : 115×260cm, Tahun : 2013, Warna : Jolawe, Benguk, Tingi, Indigo, Tegeran 


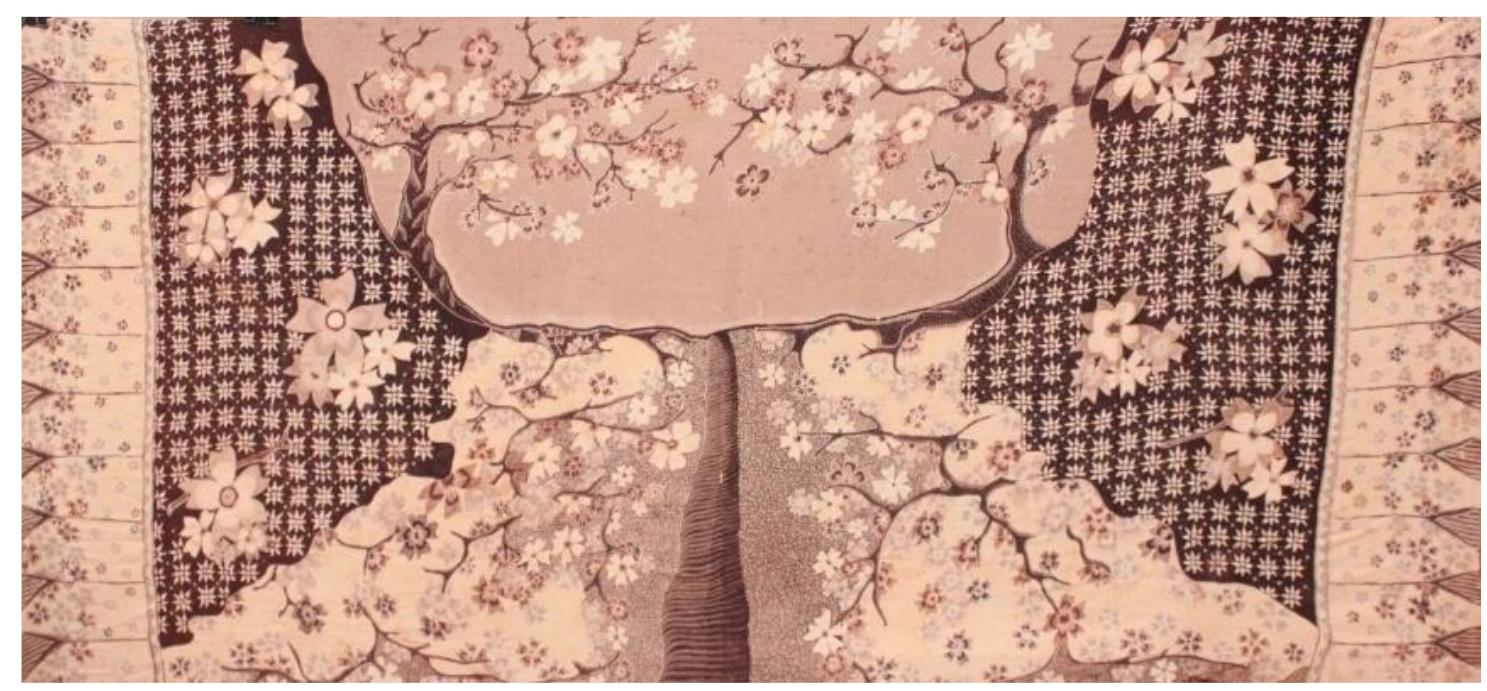

Judul : Truntum Sakura

Media : Kain Sutera, Ukuran : 115×260cm, Tahun : 2013

Warna : Jolawe, Benguk, Tingi, Indigo, Tegeran

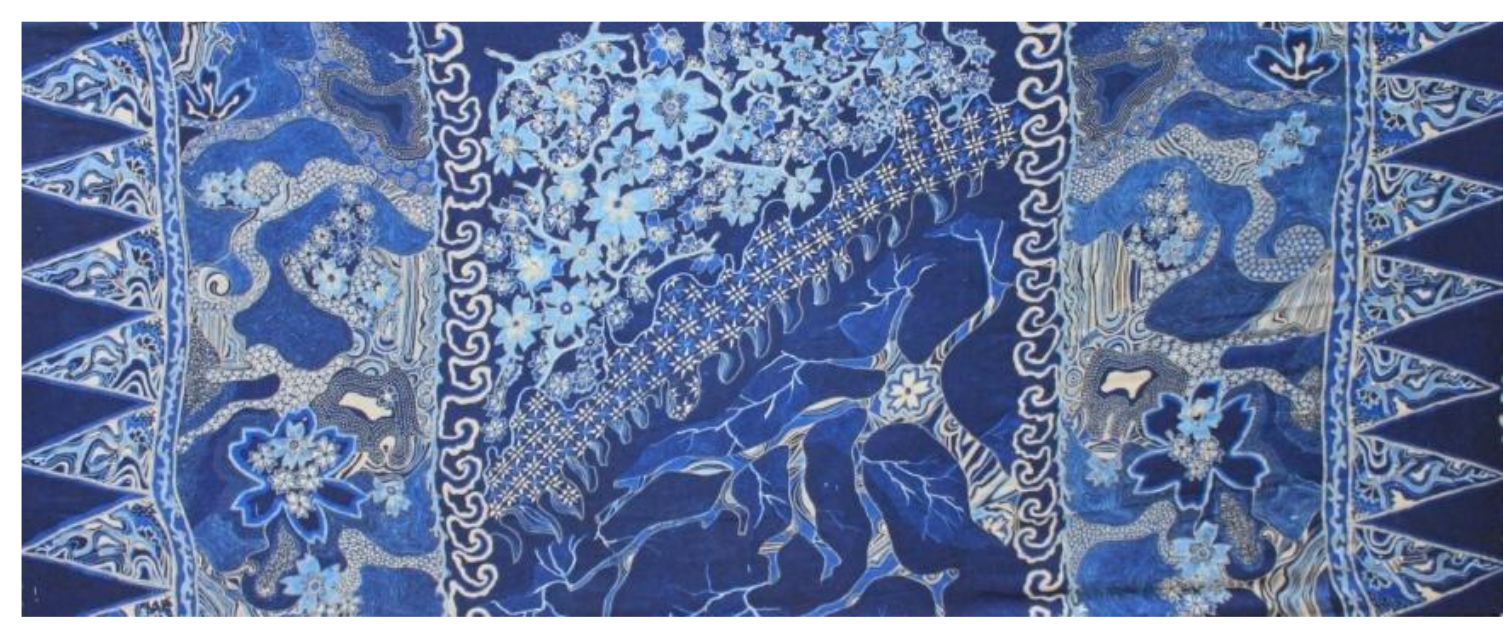

Judul : Gelombang Sakura

Media : Kain Sutera, Ukuran : 115x260cm, Tahun : 2013, Warna : Indigo, Tingi, Tegeran

Mengalir lepas dengan keindahan alam akan memunculkan suatu karya seni yang indah dalam menciptakan karya seni terutama tekstil. Objek yang ada di alam sangat menarik bila dijadikan sebagai inspirasi dalam pembuatan karya seni dengan ketulusan hati dan didasari pengalaman estetis, eksperimen warna dan teknik dari seorang seniman, untuk itu tema yang penulis angkat adalah moment atau kejadian menarik Sakura pada saat bermekaran di musim semi. Penggambaran Sakura akan terlihat indah jika bergerombolan menjadi satu, karena Sakura tidak bisa berdiri sendiri. Bentuk dari keindahan Sakura, warna yang ditampilkan dengan tekniknya akan mempunyai ciri khas tersendiri.

Dari banyak kelebihan yang dimiliki sakura, tercipta sebuah karya seni dengan mengeksplorasi bentuk desain sakura. Karya seni ini berwujud karya kain panjang. 
Hal-hal yang terkandung dalam karya seni tersebut merupakan hal yang berhubungan dengan konsep karya seni. Konsep utama yang ingin di sampaikan pada karya ini adalah tentang keindahan yang terjadi saat sakura bersemi. Menjelaskan bahwa sakura mempunyai momen khusus saat bersemi yaitu katika sakura bersemi, sakura gugur, piknik di bawah pohon sakura, terowongan sakura dan disaat seniman menstilisasai sakura dan dibentuk berjejer-jejer ternyata terbentuk truntum sakura.

Setiap karya mempunyai konsep yang berbeda-beda. Konsep karya pertama "Sakura Semi" Pada penciptaan karya pertama ini tema yang diambil adalah sakura semi. Momen dimana Sakura sedang berbungaindah-indahnya dengan macam warna yang indah, di bawah Sakura terdapat beberapa orang yang menyaksikan momen tersebut. Pegunungan Fuji nancantik menyaksikan seminya sakura. Tujuan penulis menciptakan karya ini adalah menggambarkan keindahan alam yang timbul dengan natural atau alami. Seperti halnya kita sebagai manusia dengan melihat karya ini semakin mencintai keindahan dan hiduplah seperti bunga tersebut yang menebar keindahan dan berguna untuk sesama.

Warna yang dihasilkan dari karya ini sangat berbeda dengan desain yang sudah di buat, dimana karya yang sebelum dilorod warna pada kain awalnya berwarna abuabu tajam, namun setelah dilorod karya berubah menjadi arah cokelat. Hal ini disebabkan karena warna alam mempunyai sifat ketidakpastian akan hasil akhir dan terjadi pencampuran warna satu dengan yang lainya.
Karya ke 2 dengan judul "Menonton Sakura" Karya kedua ini penulis mengambil judul karya Menonton Sakura " Hanami". Tujuannya adalah untuk mengetahui bahwa didalam Proses Sakura bersemi terdapat banyak momen yang terjadi salah satunya adalah Hanami atau yang dimaksud menonton Sakura dengan cara melihat sakura diengan berpiknik dibawah Sakura. Makan, minum-minuman, bersenda gurau dengan kekasih, sahabat, ataupun keluarga merupakan momen yang paling dirasakan ketika bisa duduk bersama di bawah Pohon Sakura. Karya ini memberi arti tentang kasih sayang, kebahagiaan antar sesama.

Karya tiga mempunyai judul "Terowongan Sakura" Membayangkan gugusan-gugusan Sakura menaungi kepala kita, sementara kaki melangkah di atas daun-daun mahkota bertebaran, rantingrating saling berdekatan dan membentuk suatu terowongan yang menarik. Keadaan tersebut di gambarkan pada kain panjang ini. Warna pada karya ini terlihat ada bercak yang muncul. Berdasarkan melihat pengalaman warna Indigo jika ditumpang dengan warna lain maka warna yang ditimbulkan terdapat bercak tidak bisa merata. Hal ini patut dicarikansolusi bagaimana caranya agar warna bisa tetapstabil atau konsisten walaupun ditumpang dengan warna lain.

Karya ke empat dengan judul "Gugur Sakura" Keadaan Sakura setelah ia bersemi beberapa hari selanjutnya ia memasuki massa mengugurkan Ranting, bunga bertebaran. Momen ini sangat indah, orang-orang tetap berdatangan dan tetap merasakan nikmat di bawah Sakura. Arti dari karya ini merupakan suatu bentuk keharmonisan, kasih sayang satu dengan 
yang lainya walaupun dalam keadaan apapun. Warna yang ditimbulkan sebelum dilorot sangatlah indah beragam dan tajam. Latar putih yang seharusnya dilorot putih karena terdapat efek warna yang lain sehingga warna jadi lebih indah yaitu cream. Setiap karya mempunyai keunikan warna tersendiri yang lembut dan unik serta mempunyai khas.

Karya ke 5 dengan judul "Badai Sakura "Badai Sakura merupaka hamparan yang unik ketika diterpa angin dan sakura berterbangan membentuk seperti badai atau angin dan angin itu membawa Sakura menari nari diatas tanah. Sungguh sangat cantik jika gambaran tersebut bisa di refleksikan ke dalam kain panjang. Karya ini merupakan proses eksperimen pemutihan dengan menggunakan warna alam.

Karya ke enam berjudul "Truntum Sakura "Judul pada karya ini adalah Truntum Sakura, Alasan yaitu ketika saat membuat sakura berjejer dengan stilasi bentuk ternyata mengarah ke truntum sehingga di beri judul truntum sakura dan bisa tergabung dengan bentuk yang menarik.. Pada obyek gambar ini Truntum sakura berada di samping kanan kiri, dengan jalan lurus terdapat spohon sakura yang sudah bersemi indah. Hal ini bermaksud untuk memberi keseimbangan jalan menuju hal yang indah dan di situ kita harus bisa seimbang.

$$
\text { Karya ke tujuh berjudul }
$$
"Gelombang Sakura" Moment yang terjadi saat Sakura bersemi dengan lepasnya bunga, dahan, ranting dan angin membawanya melayang-layang sehingga membentuk gugusangelombanggelombang yang menarik. Sakura yang digambarkan dalam kain panjang ini yaitu ketika Sakura mengembang dengan begitu indahnya dan yang satunya ketika Sakura melepaskan dahan-dahan yang menjuntai hingga terdapat Sakura yang berdiri sendiri namun tidak ada dahan hanya ranting kering. Kedua kondisi ini digabungkan dengan perantara Truntum sakura. Sakura saat mengembang mempunyai arti keindahan, kesuburan sedangkan Sakura yang hanya ranting ia sungguh sangat rentan dan tidak kokoh. Jadi dimaksudkan karya ini seperti di dalam kehidupan yang mempunyai gelombang pasang surut naik turun dan tidak selamanya kita di bawah (gambaran sakura kering) kita harus kuat untuk bisa menjadi diatas dan indah dengan semangat yang ada.

Karya ke delapan dengan judulu "Pagi Sore Sakura" Motif batik pagi sore mulai ada pada zaman penjajahan Jepang. Pada waktu itu masa-masa sulit hidup, untuk penghematan, pembatik membuat kain motif pagi sore. Yang dimaksut kain pagi sore karena dalam satu kain dibuat dengan dua desain motif yang berbeda. Pada pagi hari bisa digunakan sisi motif yang satu, untuk sore harinya dapat dikenakan motif yang berbeda dari sisi kain lainya, jadi terkesan memiliki dua kain yang berbeda padahal hanya selembar kain. Dalam karya ini terdapat satu buah eksplorasi Sakura dan sisi lain merupakan eksplorasi geometris sakura, simpel dan terkesan eksklusive.

Warna pada karya ini terdapat berbagai masalah karena menggunakan warna indigo dengan tumpangan warna alam yang lainya. Dan karya ini percobaan pertama saat pencoletan jadi proses nyolet kurang sempurna sehingga warna banyak yang luntur. Meski demikian karya pagi sore ini masih memiliki kekhasan warna yang 
berbeda dariyang lainya, ada yang kurang namun tampak elegan dan sangat indah.

\section{Kesimpulan}

Karya seni diciptakan manusia untuk mendapatkan kepuasan batin. Tidak sekedar melihat visual yang indah namun berhubungan dengan ide, konsep, dan teknik yang seimbang untuk mendapatkan hasil yang indah. Tugas Akhir dengan judul "Penciptaan Motif Sakura Pada Kain Panjang". Keindahan Sakura saat bersemi di tuangkan kedalam kain panjang.

Komposisi warna dengan warna alam soft menuansakan kekhasan kebudayaan Jepang sangat kental, tanpa menghilangkan kesan lokal yang merupakan identiti batik yang kental. Kesan lembut dan memancarkan eksotisme serta elegan tampil pada setiap helai karya. Pewarna alami mempunyai sifat yang tidak bisa ditebak warnanya. Selain itu warna alami juga ramah lingkungan sehingga menimbulkan warna yang mempunyai Cirikhas.

Berbagai macam keunikan batik warna alami mempunyai nilai seni tinggi, elegan, ekslusive serta lembut. Warnawarna alam yang digunakan untuk pewarnaan pada batik diambil dari bahanbahan yang berasal dari tumbuhan seperti bunga, daun, akar, kulit batang, kayu, buah dan lain sebagainya. Untuk menghasilkan warna yang diinginkan diperlukan waktu yang tidak sedikit karena kita membuat sampel terlebih dahulu sesuai keinginan kita. Penggoresan warna atau pencelupan warna yang dilakukan tidak hanya sekali atau duakali bahkan didalam karya ini mencapai sedikitnya duapuluh kali, sehingga dalam pewarnaan karya ini menghabiskan waktu berhari-hari bahkan hingga hitungan minggu.

Proses pembuatan zat warna alam bukan urusan gampang, cepat, murah, digemari banyak orang dan merupakan salahsatu bidang kebudayaan yang bernilai sangat tinggi dan dicintai oleh sedikit orang yang mengagumi dan mencintai bahwa mempunyai kebanggaan yang luarbiasa pada alamsemesta yang begitu kaya raya dan harus terus dilestarikan di Indonesia.

\section{DAFTAR PUSTAKA}

Djoemeno, Nian S, Batik dan Mitra "Batik and its Kinds", Jakarta: Djambatan, 1990

Fukumoto Ai, Mahasiswa Sastra Indonesia, Woman Univercity Jepang

Gustami, SP., "Proses Penciptaan Seni Kriya: Untaian Metodologis", Program Pascasarjana S2 Penciptaan Dan Pengkajian Seni ISI Yogyakarta, 2004

Kadir A, Pengantar Estetika, Yogyakarta: STSRI “ASRI", 1975

Sachari, Agus, "Desain-Desain Gaya dan Realitas", Indonesia : Studi Desain ITB, 1987

"Bunga Ceri diKagumi Sejak Masa Silam", Jepang : Majalah Sedarlah, 2000 